\title{
Covid-19: Don't forget the impact on US family physicians
}

\author{
Very big changes—very little credit or guidance
}

\section{Douglas Kamerow senior scholar, Robert Graham Center for policy studies in primary care, professor of family medicine at Georgetown University, and associate editor, The BMJ}

As covid-19 continues its exponential growth in parts of the United States, we have heard a great deal in the media about brave, exhausted emergency room doctors and staff. 12 Very little that I have seen, however, has focused on a much larger group of doctors who are also on the front lines of the war against covid-19: those who deliver primary care. In the US there are more than twice as many family doctors as ER doctors and almost three times as many pediatricians, most of whom work exclusively in primary care. ${ }^{3}$ Altogether there are more than five times more primary care doctors than ER doctors, and that is not counting general internists, many of whom in the US are also primary care doctors.

What is going on in primary care? I spoke with friends and colleagues in primary care to find out, and I heard three main points. Dramatic changes in practice have come very quickly, without much prior preparation. Little assistance, or even clear guidance, has come from authorities. And the resulting changes vary widely by practice organizational structure.

The most important thing to understand about systematic changes in US healthcare delivery is, of course, that we have no single healthcare system here. A primary care medical practice may be a small, self-owned group, part of a larger hospital system, owned by the state or federal government, or a community owned non-profit corporation. Family doctors, for example, may own their practice with full authority to set and change practice policies or they may be salaried employees who lead the clinical team but have little or no say in management. This means that there are dramatic differences in how practices have reacted to the coronavirus epidemic and in what their doctors think about those changes.

Every doctor I spoke with reported feeling whip-sawed by constantly changing guidance from experts and regulators about coronavirus testing and triage policies. They were often confused by changing recommendations from trusted sources, as well as conflicting recommendations from local, state, medical specialty, and federal authorities. They have reacted in different ways, some suspending routine well-patient visits in favor of treating only urgent and symptomatic patients. Others with larger, multi-site practices have routed high risk patients to one specific location, trying to maintain chronic care patient visits for the rest of their patients.

Once policies for testing and triage are set, practices' size and ownership affect implementation of patient communication and triage. Doctors in small, independent practices report difficulty reaching all patients before visits to appropriately triage them. Larger practices, with more resources, have larger staffs, online patient portals, apps, even outreach workers who can guide patients. Some doctors have ample supplies of the personal protective equipment that enable them to see high risk patients, while others report shortages.

One doctor told me they were switching from $90 \%$ in-person visits and $10 \%$ online virtual visits to the opposite, reducing their in-person visits to $10 \%$ of their patient encounters. Smaller practices had fewer resources to even attempt such a dramatic change. Also, salaried doctors in practices backed by large organizations were not worried about how they were going to be paid for these virtual visits or whether they could afford to keep their practice staff on payroll with dramatically declining fee-for-service income. Not so with a private practice pediatrician who was very concerned whether they were being reimbursed for telemedicine visits and worried whether they could continue to make staff payroll.

It is a very tough time for primary care medicine. It would be helped by clear policy guidance and financial assistance to enable delivery of the appropriate, safe care that all patients need and expect.

Adamy J. As coronavirus cases mount, emergency rooms strain to keep doctors on the job. Wall Street Journal. 21 Mar 2020. https://www.wsj.com/articles/as-coronavirus-casesmount-emergency-rooms-strain-to-keep-doctors-on-the-job-11584783000.

2 Dalton C. I'm an ER doctor. Please take coronavirus seriously. Guardian. 20 March 2020. https://www.theguardian.com/commentisfree/2020/mar/20/er-doctor-coronavirusexponential-growth

3 American Board of Medical Specialties. Board certified physicians per member board, in ABMS Board Certification Report 2018-2019. Sep 2019. https://www.abms.org/media/ 257753/abms-board-certification-report-2018-2019.pdf.

Published by the BMJ Publishing Group Limited. For permission to use (where not already granted under a licence) please go to http://group.bmj.com/group/rights-licensing/ permissions 
